\title{
Genetic modification of the effect of alcohol consumption on CHD
}

\author{
Lisa M. Hines \\ Department of Epidemiology, Harvard School of Public Health, 677 Huntington Avenue, Boston, \\ MA 02115, USA
}

\begin{abstract}
The deleterious health effects of high alcohol consumption are numerous and well recognized; however, the effect of moderate alcohol consumption on overall health continues to be a debated issue. Among the more prevalent diseases in Westernized countries, epidemiological research suggests that alcohol in moderation substantially reduces the risk of CHD, while it modestly increases the risk for certain cancers, such as breast and colon cancer. Despite the overwhelming data supporting the beneficial effect of moderate alcohol consumption on the cardiovascular system, some researchers are not convinced. Sceptics argue that the reduction in risk is attributed to a favourable lifestyle factor associated with moderate alcohol consumption, or that it may be attributed to constituents of alcoholic beverages other than ethanol, such as the antioxidants in the grapes. In order to promote overall health for the general public, it is necessary to elucidate these issues. One approach is to study population differences in alcohol metabolic efficiency, which is likely to contribute to an individual's susceptibility to alcoholassociated diseases. Among the population there is substantial variability in the efficiency to metabolize alcohol. Genetic variation among the alcohol-metabolizing genes is known to produce isoenzymes with distinct kinetic properties. Studying genetic differences that potentially influence disease susceptibility among populations may provide insight into the mechanism(s) for the relationship between risk factor and disease, such as alcohol and CHD.
\end{abstract}

\section{Alcohol consumption: Alcohol metabolism: CHD}

\section{Epidemiological data on the relationship between alcohol consumption and $\mathrm{CHD}$}

Epidemiological data strongly support an inverse association between moderate alcohol consumption and risk of CHD and/or CHD mortality (Grobbee et al. 1999; Sesso \& Gaziano, 1999; Rimm \& Stampfer, 2000; Gall, 2001). This relationship has been observed in diverse populations that differ in relation to incidence of CHD and preference of alcoholic beverage, such as populations from Yugoslavia, UK, Denmark, China, France and Japan (Kozararevic et al. 1980; Doll et al. 1994; Gronbaek et al. 1995; Yuan et al. 1997; Kitamura et al. 1998; Renaud et al. 1998). The reproducibility of this finding refutes previous ecological data suggesting that only wine is beneficial (Rimm et al. 1996). Taking into account other known CHD risk factors, an overall estimate from prospective studies is a $30-40 \%$ reduction in risk of $\mathrm{CHD}$ for two drinks per $\mathrm{d}$ among men and one drink per $\mathrm{d}$ among women, with minimal additional benefit for higher consumption levels. Depending on the study and the beverage type, a typical drink has been defined as containing $10-15 \mathrm{~g}$ alcohol. Evidence suggests a ' $U$ '-shaped relationship between the level of alcohol consumption and CHD, with estimates of the bottom of the curve ranging from two to six drinks/d (Grobbee et al. 1999; Rimm \& Stampfer, 2000). Recent epidemiological studies have shown that alcohol consumption on a regular basis ( $\geq 3$ or $4 \mathrm{~d} /$ week) is more beneficial than consuming the entire week's allocation in a few days (Kannel, 1988; Kauhanen et al. 1997; Mukamal et al. 2003). There is no clear evidence to suggest that there is a difference in risk of CHD between alcohol consumption with meals and alcohol consumption without meals (Mukamal et al. 2003).

Although the epidemiological evidence is overwhelming, the specific mechanism(s) for the inverse association has not been completely elucidated. Over eighty experimental studies on human subjects have examined cardiovascular effects of alcohol on lipids, coagulation factors and other cardiovascular markers (Rimm et al. 1999). 
The majority of experimental studies utilized a cross-over study design, in which biological markers were measured among participants while consuming a fixed amount of alcohol after a washout period and during abstinence. These typically short-term studies ( $<3$ months) are useful in the investigation of the effects of alcohol on biological predictors of CHD, but not necessarily on clinical events.

Based on a meta-analysis of these experimental studies, which was conducted by Rimm et al. (1999), the effect of alcohol consumption on risk of CHD is attributed to HDL (60\%), fibrinogen (20-30\%), insulin (5-10\%) and haemostatic factors $(0-5 \%)$. Observational data, simultaneously estimating the relationships between alcohol, HDL level and risk of CHD have also demonstrated that at least half the beneficial effect is attributed to HDL (Criqui et al. 1987; Langer et al. 1992). Although the protective effect of HDL is understood, the mechanism(s) by which alcohol raises HDL levels is not clear. Some investigators have speculated that alcohol may have a direct effect on the liver; it may increase hepatic production and secretion of apo and lipoprotein particles, increase triacylglycerol lipases and decrease removal of circulating HDL (Dreon \& Krauss, 1996).

The observed increase in HDL level occurs after 1-2 weeks of daily alcohol consumption and remains unless the alcohol consumption level is decreased (Rimm \& Stampfer, 2000). Early observations suggested that the effect of alcohol was only on HDL-3 particles, not HDL-2 particles, but recent work has found that it increases both types of particle (Gaziano et al. 1993; Clevidence et al. 1995). Although epidemiological evidence suggests a 'U'-shaped association between alcohol consumption and CHD risk, the relationship between the amount of alcohol consumed and HDL level is linear and extends beyond the range of moderate consumption (Rimm et al. 1999). Rimm et al. (1999) estimated that $30 \mathrm{~g}$ alcohol/d (slightly more than two drinks/d) would raise HDL by $0 \cdot 1 \mathrm{mmol} / \mathrm{l}$ $(40 \mathrm{mg} / \mathrm{l})$, which translates to a $17 \%$ reduction in risk of CHD. Gender, beverage choice or duration of study did not noticeably influence this estimate. Alcohol consumption has been shown to have a greater impact on HDL levels among subjects with baseline levels below $1.0 \mathrm{mmol} / 1$ (400 mg/l; Rimm \& Stampfer, 2000).

\section{Gender differences}

Although lifetime mortality from CHD is similar for men and women, the disease primarily affects middle-aged men and older women. Experimental studies have shown a cardio-protective effect of ovarian hormones, such as increasing HDL levels, decreasing LDL levels and other vasculo-protective effects (Farhat et al. 1996). There is evidence to suggest that moderate alcohol consumption affects oestrogen levels, which could contribute to the beneficial effect of alcohol consumption on the risk of CHD (Purohit, 1998). However, recent clinical trial data do not support previous epidemiological data of a protective effect for exogenous oestrogens, specifically postmenopausal hormone therapy (Rossouw et al. 2002). Since the incidence of CHD in premenopausal women is very low, it is difficult to assess the association between alcohol consumption and CHD risk in this population. Epidemiological studies support a protective effect of alcohol consumption on CHD risk in post-menopausal women, and this benefit appears to be associated with levels of alcohol consumption that are lower than those observed for men (one drink/d v. two drinks/d; Grobbee et al. 1999). The gender difference has been attributed to three main factors: (1) body size; (2) alcohol solubility; (3) efficiency of alcohol metabolism (Meister et al. 2000). Women generally have a smaller body size and a higher proportion of body fat. Since alcohol is more soluble in body water than in body fat, the physiological effects of alcohol occur at a lower dose among women (Goist \& Sutker, 1985). Furthermore, experimental data indicate that men and women differ in relation to their efficiency in alcohol metabolism (Frezza et al. 1990). This difference could be attributed to factors such as hormones, which affect regulation of the alcohol metabolic pathway (Teschke \& Heymann, 1982; Teschke et al. 1986; Qulali et al. 1991).

\section{Genetic variation of metabolic genes and disease: a possible link to a 'causal' interpretation}

The majority of associations obtained from epidemiological studies are based on observational data. Since these studies are conducted in a non-randomized setting, they are susceptible to confounding variables. Some investigators argue that the observed inverse association between moderate alcohol consumption and CHD is attributed to other favourable lifestyle factors (Hart et al. 1999). As a result of the observed increase in risk for certain cancers, the questionable causality of the association with CHD and the fear of promoting alcohol abuse among susceptible individuals, the use of moderate alcohol consumption for overall health remains controversial. A randomized clinical trial would be ideal for validating observational data; however, this approach may not be feasible because of the potential detrimental effects of moderate alcohol consumption. An alternative approach is to study the effect of genetic variation among genes that contribute to metabolism or transduction of the suspected factor associated with a given disease. An observed modifying effect of genetic differences (e.g. a specific genotype) among alcoholmetabolizing genes on the relationship between alcohol consumption and CHD adds support to a causal interpretation of the observed association for two main reasons. First, it is unlikely that an individual's genetic composition is associated with any of the potentially confounding variables, such as smoking or exercise. Furthermore, functional genetic differences in metabolic genes will improve the possibility of identifying the specific disease-causing factors. Unlike animal experimental models, human subjects are exposed to a complex mixture of many compounds. Identifying the key factor that predisposes an individual to a given disease is difficult. For example, some sceptics argue that the reduction in risk of CHD is attributed to constituents of alcoholic beverages other than ethanol, such as the antioxidants in the grapes (Frankel et al. 1993; Whitehead et al. 1995; Bell et al. 2000). Since the predominant function of alcohol-metabolizing genes is to metabolize ethanol rather than other constituents in 


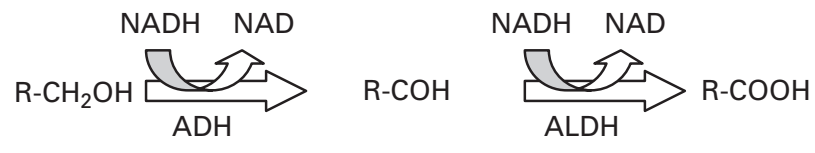

Alcohol Acetaldehyde Acetate

Fig. 1. Alcohol metabolic pathway. $A D H$, alcohol dehydrogenase; ALDH, acetaldehyde dehydrogenase.

alcoholic beverages, an observed modifying effect of genetic differences in alcohol-metabolizing genes on the relationship between alcohol consumption and CHD would suggest that ethanol is responsible for the association between alcohol consumption and alcohol-related diseases.

The Human Genome Project has demonstrated that many genes contain variants, several of which are likely to have an impact on function. Traditional epidemiological methods have been successful in identifying several lifestyle and environmental factors that contribute to disease susceptibility. However, lifestyle and environmental factors alone are not the only contributors to disease susceptibility. The ability to incorporate genetic differences will provide another perspective to the understanding of disease aetiology.

\section{The genetics of alcohol metabolism}

The pharmaco-kinetics of alcohol metabolism have been well studied. The initial steps of the predominant pathway for metabolizing alcohol are illustrated in Fig. 1. The ratelimiting step in this pathway is believed to be the oxidation of alcohol to acetaldehyde by the alcohol dehydrogenase (ADH) enzyme, a dimeric protein that consists of two $40 \mathrm{kDa}$ subunits (Bosron et al. 1988). In man there are at least seven $A D H$ genes that convert alcohol to acetaldehydes (Osier et al. 2002). Located in tandem on chromosome 4, the $A D H$ are divided into five different classes depending on their preferential substrate. The class I enzymes, encoded by $A D H 1 A, A D H 1 B$ and $A D H 1 C$ (also known as $A D H 1, A D H 2$ and $A D H 3)$, predominantly metabolize short-chain alcohols such as ethanol. The class I ADH isoenzymes share approximately $93 \%$ homology, but differ in their substrate specificity and tissue expression (Niederhut et al. 2001).

Among the class I genes, both $A D H 1 B$ and $A D H 1 C$ have polymorphisms that have been well characterized (Bosron et al. 1988). At the $A D H I B$ locus, the $\beta_{1}$ allele differs from the other alleles by one amino acid: position 47 (arginine to histidine) for the $\beta_{2}$ allele; position 369 (arginine to cysteine) for the $\beta_{3}$ allele. At the ADHIC locus, the $\gamma_{1}$ allele differs from the $\gamma_{2}$ allele by two amino acids at positions 271 (arginine to glycine) and 349 (isoleucine to valine). In vitro studies have shown that these polymorphisms produce enzymes with distinct kinetic properties (Table 1). At the $A D H 1 B$ locus, the $\beta_{2}$ homodimer is approximately forty times faster than the $\beta_{1}$ homodimer. The difference in kinetic activity at the $A D H I C$ locus is not as dramatic; the $\gamma_{1}$ homodimer is approximately 2.5 times faster than the $\gamma_{2}$ homodimer. This difference is thought to affect the rate of oxidation of blood ethanol
Table 1. The kinetic characteristics of the alcohol dehydrogenase (ADH) subunits ADH1B and ADH1C (Bosron et al. 1988)

\begin{tabular}{lcccccc}
\hline & \multicolumn{3}{c}{ ADH1B } & & \multicolumn{2}{c}{ ADH1C } \\
\cline { 2 - 4 } \cline { 6 - 7 } Homodimer .... & $\beta_{1} \beta_{1}$ & $\beta_{2} \beta_{2}$ & $\beta_{3} \beta_{3}$ & & $\gamma_{1} \gamma_{1}$ & $\gamma_{2} \gamma_{2}$ \\
\hline Maximum velocity (/min) & 9.2 & 400 & 270 & & 87 & 35 \\
\hline
\end{tabular}

Table 2. Allele frequencies (\%) of the alcohol dehydrogenase $(A D H)$ polymorphisms $A D H 1 B$ and $A D H 1 C$ by ethnicity (Bosron et al. 1988; McCarver et al. 1997)

$A D H 1 B^{*} 1 A D H 1 B^{*} 2 A D H 1 B^{*} 3 A D H 1 C^{*} 1 A D H 1 C^{*} 2$

\begin{tabular}{lllllr} 
Population & $\left(\beta_{1}\right)$ & $\left(\beta_{2}\right)$ & $\left(\beta_{3}\right)$ & $\left(\gamma_{1}\right)$ & $\left(\gamma_{2}\right)$ \\
\hline Caucasian & $90-95$ & $<5$ & $<5$ & 60 & 40 \\
Asian & 35 & 65 & $<5$ & 95 & 5 \\
African- & 75 & $<5$ & 25 & 85 & 15 \\
$\quad$ American & & & & &
\end{tabular}

(Bosron et al. 1988), although the $A D H 1 C$ polymorphism had no apparent effect on blood alcohol levels in a shortterm study of high-dose alcohol consumption in human subjects (Whitfield, 1994).

The allele frequencies of the class I $A D H$ polymorphisms vary depending on the ethnic background of the population (Table 2). Among Caucasian populations, the predominant allele at the $A D H 1 B$ locus encodes for $\beta_{1}$, the slowest-oxidizing subunit; the $\beta_{2}$ and $\beta_{3}$ alleles are quite rare $(<5 \%)$. At the $A D H 1 C$ locus, there is a relatively even distribution of the $\gamma_{1}$ and $\gamma_{2}$ alleles, with the $\gamma_{1}$ allele being slightly more common.

Multiple molecular forms of acetaldehyde dehydrogenase (ALDH1A1 and ALDH2), the next step in the alcohol metabolic pathway, have also been identified. A variant form of $A L D H 2(A L D H 2 * 2)$, predominantly observed in Asian populations, has low acetaldehyde-oxidizing activity, which results in a facial flushing response associated with the toxicity of acetaldehyde (Takeshita et al. 1994). This variant has been shown to be protective against the development of alcoholism (Thomasson et al. 1991; Higuchi et al. 1995; Chen et al. 1996).

In addition to genetic determinants, the efficiency of alcohol metabolism is also affected by factors that can regulate the activity of the genes involved in alcohol metabolism. Glucocorticoids, growth hormone and retinoids have been shown to induce ADH activity (Dong et al. 1988; Potter et al. 1989; Duester et al. 1991). Furthermore, other systems such as the microsomal ethanol-oxidizing system, also contribute to alcohol metabolism (Lieber, 1999). To what extent these factors contribute to population variability in alcohol metabolism needs to be determined.

\section{Alcohol dehydrogenase-1C gene, alcohol consumption, HDL levels and risk of myocardial infarction}

Genetic determinants of alcohol metabolic capacity could play a role in the susceptibility to alcohol-related diseases, 
such as CHD. Although the difference in kinetic activity among the $\beta$ subunits is considerably greater than that among the $\gamma$ subunits, the homogeneity at the $A D H 1 B$ locus among Caucasian populations suggests that the ADHIC polymorphism may contribute more to variability in metabolic capacity at the population level. The variant ADHIC allele is common and functional, making it an ideal candidate for molecular epidemiology studies among Caucasian populations.

The relationship between the ADHIC polymorphism, alcohol consumption and risk of myocardial infarction was investigated in a case-control study nested within the prospective Physicians' Health Study cohort, a predominantly Caucasian population (Hines et al. 2001). It was hypothesized that if ethanol is responsible for the observed beneficial effect on risk of CHD, a slower rate of clearance of ethanol may enhance the beneficial effect of moderate alcohol consumption on the risk of CHD. In addition, the relationship between alcohol intake and $A D H 1 C$ genotype on plasma HDL levels was examined among this study population and in a similar cohort of women.

The Physicians' Health Study commenced in 1982 as a randomized double-blinded placebo-controlled trial of aspirin and $\beta$-carotene (Steering Committee of the Physician's Health Study Research Group, 1989). It consisted of 22071 US male physicians between the ages of 40 and 84 years without a previous diagnosis of myocardial infarction or stroke. Before randomization, a blood sample was requested from all the participants. Specimens were received from $68 \%$ of the physicians who form the baseline cohort for this study (Ma et al. 1996).

Information on cardiovascular risk factors and disease status was obtained through biannual mailings and medical records. Follow-up for fatal and non-fatal outcomes was 99\%. By 1994, 396 eligible incident myocardial infarction cases were identified. When possible, each case was matched to two randomly-selected control subjects based on age, smoking status and time from randomization, yielding a total of 1166 individuals (396 cases and 770 controls).

A strong interaction between the $A D H I C$ genotype and the level of alcohol consumption in relation to the HDL level and the risk of myocardial infarction was observed (Hines et al. 2001). Homozygosity for the slow-oxidizing allele $\left(\gamma_{2}\right)$ was associated with a reduced risk of myocardial infarction (relative risk, $0.65 ; 95 \% \mathrm{CI}, 0.43,0.99$ ). Moderate alcohol consumption was associated with decreased risk for all genotypes; however, $A D H I C$ genotype modified this association $(P=0 \cdot 01)$. Among men who were homozygous for the fast-oxidizing allele $\left(\gamma_{1}\right)$, daily drinkers had a relative risk of $0.62(95 \% \mathrm{CI}, 0.34,1 \cdot 13)$ compared with men consuming less than one drink per week. Daily drinkers who were homozygous for the slowoxidizing allele $\left(\gamma_{2}\right)$ had a larger and highly significant $86 \%$ reduced risk (relative risk, $0 \cdot 14 ; 95 \% \mathrm{CI}, 0 \cdot 04,0 \cdot 45$; Fig. 2). Furthermore, slow oxidizers who consumed alcohol daily had higher plasma HDL levels $(P=0.05)$.

The interaction between $A D H 1 C$ genotype, alcohol consumption and plasma levels of HDL was confirmed in an independent study of 325 post-menopausal women not taking hormone-replacement therapy $(P=0.02$; Hines et al.

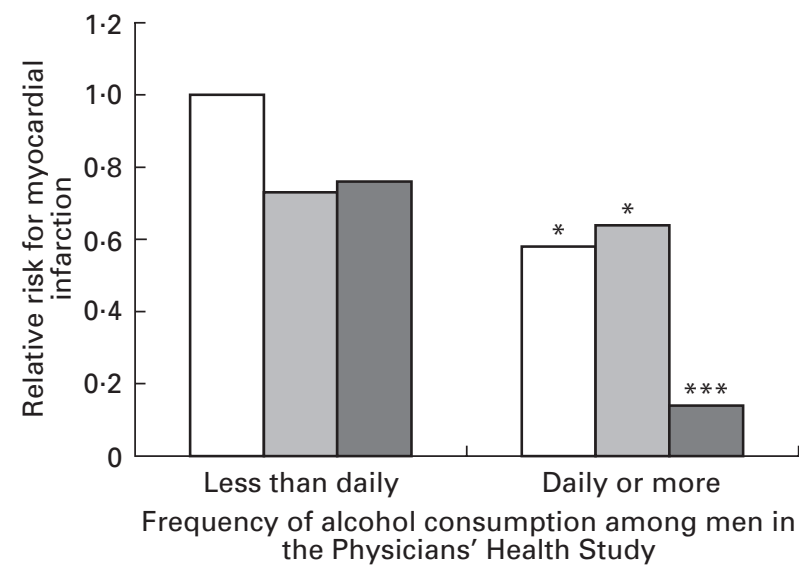

Fig. 2. Multivariate relative risks for myocardial infarction $v$. aldehyde dehydrogenase-3 genotype and daily alcohol consumption ( $P=0.02$ for interaction). ( $\square$ ), Fast oxidisers, individuals homozygous for the $\gamma_{1}$ allele; $(\square)$, intermediate oxidisers, individuals heterozygous for the $\gamma_{1}$ allele; $(\square)$, slow oxidisers, individuals homozygous for the $\gamma_{2}$ allele. In addition to the matching factors of age, smoking use and follow-up time, adjustment was made for BMI, vigorous physical activity, family history of myocardial infarction, assignment to aspirin use and history of hypertension, diabetes or angina at enrollment. Mean values were significantly different from those for fast oxidizers who consumed less than one drink daily: ${ }^{\star} P=0.04,{ }^{* \star *} P<0.001$; relative risk was $0.14(95 \% \mathrm{Cl}$ $0.04,0.42)$.

2001). These women were participants in a nested casecontrol study of breast cancer among the 33826 Nurses' Health Study participants who donated blood in 1989-90, as described elsewhere (Haiman et al. 1999).

The data of Hines et al. (2001) suggest that moderate drinkers who are homozygous for the slow-oxidizing ADHIC allele $\left(\gamma_{2}\right)$ have higher HDL levels and a substantially decreased risk of myocardial infarction. Since the predominant function of $\mathrm{ADH} 1 \mathrm{C}$ is to metabolize ethanol, this study strengthens the evidence that the reduction in the risk of heart disease is attributed to the ethanol in alcoholic beverages.

\section{Additional studies}

Other studies have also assessed the relationship between genetic differences in alcohol metabolism, alcohol consumption and cholesterol levels. Nakamura et al. (2002) studied the variation at the $A L D H 2$ locus among a Japanese population. They did not observe any modifying effect of the $A L D H 2$ genotype on the relationship between alcohol consumption and HDL levels. However, because of the strong toxicity of acetaldehyde, individuals with the variant $A L D H 2$ allele consumed virtually no alcohol. Among the sixty-eight men and ninety-six women who were homozygous for the variant $A L D H 2$ allele, only six men and two women consumed more than half a drink per week. The immediate physiological effects observed among individuals with the variant $A L D H 2$ allele is a strong influential factor on the amount of alcohol consumed, as reflected by its protective effect on alcoholism (Thomasson et al. 1991; Higuchi et al. 1995; Chen et al. 1996). Thus, 
this population may not be ideal for investigating the relationship between alcohol metabolism and cholesterol levels.

Hashimoto et al. (2002) studied the relationship between variation at the $A D H 1 B$ and $A L D H 2$ loci, alcohol consumption and serum lipids among a Japanese population who consumed high amounts of alcohol. The study population consisted of 133 male hospital employees who reportedly consumed $>300 \mathrm{~g} /$ week, which is equivalent to more than twenty-three drinks per week. To what extent the ADH system contributes to alcohol metabolism at high levels of alcohol consumption is unclear. Previous evidence suggests that other alcohol-metabolizing systems, such as the microsomal ethanol-oxidizing system, play a more substantial role in alcohol metabolism at high levels of alcohol consumption (Lieber, 1999). Surprisingly, the authors did not observe a marked difference in alcohol consumption level based on $A L D H 2$ genotype among this population. This finding could be partially attributed to the fact that the heterozygotes and the homozygotes for the $A L D H 2 * 2$ allele were combined into one category, although previous data suggest that heterozygotes also experience facial flushing (Takeshita et al. 1994). Individuals with the variant $A L D H 2 * 2$ had noticeably higher HDL levels than those who did not $(820 \mathrm{mg} / \mathrm{l}(2 \cdot 12 \mathrm{mmol} / \mathrm{l}) \quad v .650 \mathrm{mg} / \mathrm{l}$ $(1.68 \mathrm{mmol} / \mathrm{l}))$. At the $A D H 1 B$ locus, higher HDL levels were observed among individuals homozygous for the slow-oxidizing allele $\left(\beta_{1}\right)$ compared with either heterozygotes or homozygotes for the fast-oxidizing allele $\left(\beta_{2} ; 708 \mathrm{mg} / \mathrm{l}(1.83 \mathrm{mmol} / \mathrm{l}), 634 \mathrm{mg} / \mathrm{l}(1.64 \mathrm{mmol} / \mathrm{l})\right.$ and $634 \mathrm{mg} / \mathrm{l}(1.64 \mathrm{mmol} / \mathrm{l})$ respectively). These observations were not statistically significant; however, the sample size of this study was small. Although previous evidence suggests that other alcohol-metabolizing systems play a greater role in alcohol metabolism at high levels of alcohol consumption, these data do support a role of $\mathrm{ADH}$ in the effect of alcohol consumption on HDL levels.

Whitfield et al. (2003) investigated the individual effects of both the $A D H 1 B$ and $A D H 1 C$ polymorphisms on the relationship between alcohol consumption and HDL levels among an Australian population that was originally selected for a twin study. The authors observed no modifying effect for either of the variant genes. This inconsistency could be attributed to differences in the study populations. Whitfield et al. (2003) studied a population that consisted of both men and women, with the age for the women ranging from 29 to 92 years. Data were only presented for men and women, pre- and post-menopausal, combined. In the Hines et al. (2001) study, this interaction was observed only among men and post-menopausal women who were not taking post-menopausal hormones. Premenopausal women and post-menopausal women who use postmenopausal hormones are known to have substantially higher HDL levels compared with men and post-menopausal women who do not use post-menopausal hormones (Wenger, 1996). Among post-menopausal hormone users, the composition, dosage and period of usage are also likely to influence HDL levels. The effect of metabolic capacity on HDL levels and CHD risk among individuals who have oestrogen-elevated HDL levels has not been elucidated. The lack of effect modification by $A D H 1 C$ genotype could suggest a threshold for HDL level. Thus, individuals with oestrogen-elevated HDL levels may receive minimal additional increases in the HDL level from alcohol consumption, which can be supported by experimental data suggesting no effect of alcohol consumption on HDL levels among runners who have exercise-elevated HDL levels (Hartung et al. 1983, 1993). Alternatively, the specificity of the observed $A D H 1 C$-alcohol interaction could be attributed to the regulatory effect of oestradiol on $\mathrm{ADH}$. Animal studies have demonstrated that oestradiol administration results in an induction of $A D H$ expression and an increase in $\mathrm{ADH}$ activity, which is likely to affect the rate of alcohol metabolism (Teschke \& Heymann, 1982; Teschke et al. 1986; Qulali et al. 1991).

\section{Conclusion}

There is substantial epidemiological and experimental evidence to support a strong inverse relationship between moderate alcohol consumption and CHD; however, the basis for this relationship is not completely understood. The physiological effects of alcohol and the mechanisms for alcohol metabolism have been well studied, but the means by which alcohol affects the cardiovascular system in relation to $\mathrm{CHD}$ risk are complex and unclear. In addition to the intricacies of alcohol metabolism, a number of in vitro studies have shown that ethanol influences gene expression in a variety of genes that may ultimately contribute to the development of heart disease, such as PPAR $\alpha$ (Galli et al. 2001), cytochrome P450 2E1 (Ingelman-Sundberg et al. 1994), c-myc (Paice et al. 1996), tissue-type plasminogen activator (Grenett et al. 1998), urokinase-type plasminogen activator (Grenett et al. 1998) and plasminogen activator inhibitor-1 (Grenett et al. 2000). It is now well recognized that many diseases cannot be attributed to a single cause, but rather a combination of several contributing factors. Furthermore, these factors will not necessarily be the same for every individual. Thus, it is important to assess both genetic and lifestyle factors in order to improve our understanding of the pathogenesis of disease. Advances in genomic and proteomic research will provide a more comprehensive approach to elucidating disease development at a sophisticated level of molecular detail. A more complete understanding of these elaborate mechanisms will assist in making recommendations at the individual level, which would be the most effective means for promoting overall health. Furthermore, with any medical advice where there is risk and benefit; caution should be exercised in framing guidelines for alcohol and they should be kept in the larger context of other favourable lifestyle factors, such as exercise and diet.

\section{References}

Bell JR, Donovan JL, Wong R, Waterhouse AL, German JB, Walzem RL \& Kasim-Karakas SE (2000) (+)-Catechin in human plasma after ingestion of a single serving of reconstituted red wine. American Journal of Clinical Nutrition 71, 103-108.

Bosron WF, Lumeng L \& Li TK (1988) Genetic polymorphism of enzymes of alcohol metabolism and susceptibility to 
alcoholic liver disease. Molecular Aspects of Medicine 10, 147-158.

Chen WJ, Loh EW, Hsu YP, Chen CC, Yu JM \& Cheng ATA (1996) Alcohol-metabolizing genes and alcoholism among Taiwanese Han men. British Journal of Psychiatry 168, $762-767$.

Clevidence BA, Reichman ME, Judd JT, Muesing RA, Schatzkin A, Schaefer EJ, Li Z, Jenner J, Brown CC, Sunkin M, Campbell WS \& Taylor PR (1995) Effects of alcohol consumption on lipoproteins of premenopausal women: A controlled diet study. Arteriosclerosis, Thrombosis and Vascular Biology 15, 179-184.

Criqui MH, Cowan LD, Tyroler HA, Bangdiwala S, Heiss G, Wallace RB \& Cohn R (1987) Lipoproteins as mediators for the effects of alcohol consumption and cigarette smoking on cardiovascular mortality: results from the Lipid Research Clinics Follow-up Study. American Journal of Epidemiology 126, 629-637.

Doll R, Peto R, Hall E, Wheatley K \& Gray R (1994) Mortality in relation to consumption of alcohol: 13 years' observations on male British doctors. British Medical Journal 309, 911-918.

Dong Y, Poellinger L, Okret S, Hoog JO, von Bahr-Lindstrom H, Jornvall H \& Gustafsson JA (1988) Regulation of gene expression of class I alcohol dehydrogenase by glucocorticoids. Proceedings of the National Academy of Sciences USA 85, 767-771.

Dreon DM \& Krauss RM (1996) Alcohol, lipids, and lipoproteins. In Alcohol and the Cardiovascular System. NIH Publication no. 96-4133, pp. 369-391 [S Zahkari and M Wassef, editors]. Bethesda, MD: National Institutes of Health.

Duester G, Shean ML, McBride SM \& Stewart MJ (1991) Retinoic acid response element in the human alcohol dehydrogenase gene ADH3: Implications for regulation of retinoic acid synthesis. Molecular Cell Biology 11, 1638-1646.

Farhat MY, Myers AK \& Ramwell PW (1996) Alcohol, coronary artery disease, and estrogen. In Alcohol and the Cardiovascular System. NIH Publication no. 96-4133, pp. 647-661 [S Zahkari and $\mathrm{M}$ Wassef, editors]. Bethesda, MD: National Institutes of Health.

Frankel EN, Kanner J, German JB, Parks E \& Kinsella JE (1993) Inhibition of oxidation of human low-density lipoprotein by phenolic substances in red wine. Lancet 341, 454-457.

Frezza M, di Padova C, Pozzato G, Terpin M, Baraona E \& Lieber CS (1990) High blood alcohol levels in women. The role of decreased gastric alcohol dehydrogenase activity and first-pass metabolism. New England Journal of Medicine 322, 95-99.

Gall N (2001) Is wine good for your heart? A critical review. Postgraduate Medical Journal 77, 172-176.

Galli A, Pinaire J, Fischer M, Dorris R \& Crabb DW (2001) The transcriptional and DNA binding activity of peroxisome proliferator-activated receptor alpha is inhibited by ethanol metabolism. Journal of Biological Chemistry 276, 68-75.

Gaziano JM, Buring JE, Breslow JL, Goldhaber SZ, Rosner B, VanDenburgh M, Willett W \& Hennekens CH (1993) Moderate alcohol intake, increased levels of high-density lipoprotein and its subfractions, and decreased risk of myocardial infarction. New England Journal of Medicine 329, 1829-1834.

Goist KC Jr \& Sutker PB (1985) Acute alcohol intoxication and body composition in women and men. Pharmacology Biochemistry and Behaviour 22, 811-814.

Grenett HE, Aikens ML, Tabengwa EM, Davis GC \& Booyse FM (2000) Ethanol downregulates transcription of the PAI-1 gene in cultured human endothelial cells. Thrombosis Research 97, 247-255.
Grenett HE, Aikens ML, Torres JA, Demissie S, Tabengwa EM, Davis GC \& Booyse FM (1998) Ethanol transcriptionally upregulates t-PA and u-PA gene expression in cultured human endothelial cells. Alcoholism, Clinical and Experimental Research 22, 849-853.

Grobbee DE, Rimm EB, Keil U \& Renaud S (1999) Overview of health issues related to alcohol consumption. In Health Issues Related to Alcohol Consumption, pp. xii-xxvi [I MacDonald, editor]. Oxford: Blackwell Science Ltd.

Gronbaek M, Deis A, Sorensen TI, Becker U, Schnohr P \& Jensen $G$ (1995) Mortality associated with moderate intakes of wine, beer, or spirits. British Medical Journal 310, 1165-1169.

Haiman CA, Hankinson SE, Spiegelman D, Colditz GA, Willett WC, Speizer FE, Kelsey KT \& Hunter DJ (1999) The relationship between a polymorphism in CYP17 with plasma hormone levels and breast cancer. Cancer Research 59, 1015-1020.

Hart CL, Smith GD, Hole DJ \& Hawthorne VM (1999) Alcohol consumption and mortality from all causes, coronary heart disease, and stroke: results from a prospective cohort study of Scottish men with 21 years of follow up. British Medical Journal 318, 1725-1729.

Hartung GH, Foreyt JP, Mitchell RE, Mitchell JG, Reeves RS \& Gotto AM Jr (1983) Effect of alcohol intake on high-density lipoprotein cholesterol levels in runners and inactive men. Journal of the American Medical Association 249, 747-750.

Hartung GH, Lawrence SJ, Reeves RS \& Foreyt JP (1993) Effect of alcohol and exercise on postprandial lipemia and triglyceride clearance in men. Atherosclerosis 100, 33-40.

Hashimoto Y, Nakayama T, Futamura A, Omura M, Nakarai H \& Nakahara K (2002) Relationship between genetic polymorphisms of alcohol-metabolizing enzymes and changes in risk factors for coronary heart disease associated with alcohol consumption. Clinical Chemistry 48, 1043-1048.

Higuchi S, Matsushita S, Murayama M, Takagi S \& Hayashida M (1995) Alcohol and aldehyde dehydrogenases polymorphisms and the risk for alcoholism. American Journal of Psychiatry 152, 1219-1221.

Hines LM, Stampfer MJ, Ma J, Gaziano JM, Ridker PM, Hankinson SE, Sacks F, Rimm EB \& Hunter DJ (2001) Genetic variation in alcohol dehydrogenase and the beneficial effect of moderate alcohol consumption on myocardial infarction. New England Journal of Medicine 344, 549-555.

Ingelman-Sundberg M, Ronis MJ, Lindros KO, Eliasson E \& Zhukov A (1994) Ethanol-inducible cytochrome P4502E1: regulation, enzymology and molecular biology. Alcohol and Alcoholism 2, Suppl., 131-139.

Kannel WB (1988) Alcohol and cardiovascular disease. Proceedings of the Nutrition Society 47, 99-110.

Kauhanen J, Kaplan GA, Goldberg DE \& Salonen JT (1997) Beer binging and mortality: results from the Kuopio ischaemic heart disease risk factor study, a prospective population based study. British Medical Journal 315, 846-851.

Kitamura A, Iso H, Sankai T, Naito Y, Sato S, Kiyama M, Okamura T, Nakagawa Y, Iida M, Shimamoto T \& Komachi Y (1998) Alcohol intake and premature coronary heart disease in urban Japanese men. American Journal of Epidemiology 147, 59-65.

Kozararevic D, McGee D, Vojvodic N, Racic Z, Dawber T, Gordon T \& Zukel W (1980) Frequency of alcohol consumption and morbidity and mortality: The Yugoslavia Cardiovascular Disease Study. Lancet i, 613-616.

Langer RD, Criqui MH \& Reed DM (1992) Lipoproteins and blood pressure as biological pathways for effect of moderate alcohol consumption on coronary heart disease. Circulation $\mathbf{8 5}$, 910-915. 
Lieber CS (1999) Microsomal ethanol-oxidizing system (MEOS): the first 30 years (1968-1998) - a review. Alcoholism, Clinical and Experimental Research 23, 991-1007.

McCarver DG, Thomasson HR, Martier SS, Sokol RJ \& Li TK (1997) Alcohol dehydrogenase-2*3 allele protects against alcohol-related birth defects among African Americans. Journal of Pharmacology and Experimental Therapeutics 283, 1095-1101.

Ma J, Stampfer MJ, Hennekens CH, Frosst P, Selhub J, Horsford J, Malinow MR, Willett WC \& Rozen R (1996) Methylenetetrahydrofolate reductase polymorphism, plasma folate, homocysteine, and risk of myocardial infarction in US physicians. Circulation 94, 2410-2416.

Meister KA, Whelan EM \& Kava R (2000) The health effects of moderate alcohol intake in humans: an epidemiologic review. Critical Reviews in Clinical Laboratory Sciences 37, 261-296.

Mukamal KJ, Conigrave KM, Mittleman MA, Camargo CA Jr, Stampfer MJ, Willett WC \& Rimm EB (2003) Roles of drinking pattern and type of alcohol consumed in coronary heart disease in men. New England Journal of Medicine 348, $109-118$.

Nakamura Y, Amamoto K, Tamaki S, Okamura T, Tsujita Y, Ueno Y, Kita Y, Kinoshita M \& Ueshima H (2002) Genetic variation in aldehyde dehydrogenase 2 and the effect of alcohol consumption on cholesterol levels. Atherosclerosis 164, 171-177.

Niederhut MS, Gibbons BJ, Perez-Miller S \& Hurley TD (2001) Three-dimensional structures of the three human class I alcohol dehydrogenases. Protein Science 10, 697-706.

Osier MV, Pakstis AJ, Soodyall H, Comas D, Goldman D, Odunsi A et al. (2002) A global perspective on genetic variation at the ADH genes reveals unusual patterns of linkage disequilibrium and diversity. American Journal of Human Genetics 71, 84-99.

Paice AG, Hesketh JE, Richardson PJ \& Preedy VR (1996) The effect of starvation and ethanol on c-myc messenger RNA expression in the heart. Biochemical Society Transactions 24, 212SAbstr.

Potter JJ, Yang VW \& Mezey E (1989) Influence of growth hormone on the synthesis of rat liver alcohol dehydrogenase in primary hepatocyte culture. Archives of Biochemistry and Biophysics 274, 548-555.

Purohit V (1998) Moderate alcohol consumption and estrogen levels in postmenopausal women: A review. Alcoholism, Clinical and Experimental Research 22, 994-997.

Qulali M, Ross MA \& Crabb DW (1991) Estradiol induces class I alcohol dehydrogenase activity and mRNA in kidney of female rats. Archives of Biochemistry and Biophysics 288, 406-413.

Renaud SC, Gueguen R, Schenker J \& d'Houtaud A (1998) Alcohol and mortality in middle-aged men from eastern France. Epidemiology 9, 184-188.

Rimm EB, Klatsky A, Grobbee D \& Stampfer MJ (1996) Review of moderate alcohol consumption and reduced risk of coronary heart disease: Is the effect due to beer, wine, or spirits? British Medical Journal 312, 731-736.
Rimm EB \& Stampfer MJ (2000) Alcohol abstinence: A risk factor for coronary artery disease. In Heart Disease Update Series, vol. 2, no. 3, pp. 1-10 [E Braunwald, editor]. Philadelphia, PA: W.B. Saunders Company.

Rimm EB, Williams P, Fosher K, Criqui M \& Stampfer MJ (1999) Moderate alcohol intake and lower risk of coronary heart disease: meta-analysis of effects on lipids and haemostatic factors. British Medical Journal 319, 1523-1528.

Rossouw JE, Anderson GL, Prentice RL, LaCroix AZ, Kooperberg C, Stefanick ML, Jackson RD, Beresford SA, Howard BV, Johnson KC, Kotchen JM \& Ockene J; Writing Group for the Women's Health Initiative Investigators (2002) Risks and benefits of estrogen plus progestin in healthy postmenopausal women: principal results from the Women's Health Initiative randomized controlled trial. Journal of the American Medical Association 288, 321-333.

Sesso HD \& Gaziano JM (1999) Alcohol intake and cardiovascular morbidity and mortality. Current Opinion in Nephrology and Hypertension 8, 353-357.

Steering Committee of the Physician's Health Study Research Group (1989) Final report of the aspirin component of the ongoing physician's health study. New England Journal of Medicine 321, 129-135.

Takeshita T, Morimoto K, Mao X, Hashimoto T \& Furuyama J (1994) Characterization of the three genotypes of low Km aldehyde dehydrogenase in a Japanese population. Human Genetics 94, 217-223.

Teschke R \& Heymann K (1982) Effect of sex hormones on the activities of hepatic alcohol-metabolizing enzymes in male rats. Enzyme 28, 268-277.

Teschke R, Wannagat FJ, Lowendorf F \& Strohmeyer G (1986) Hepatic alcohol metabolizing enzymes after prolonged administration of sex hormones and alcohol in female rats. Biochemical Pharmacology 35, 521-527.

Thomasson HR, Edenberg HJ, Crabb DW, Mai XL, Jerome RE, Li TK, Wang SP, Lin YT, Lu RB \& Yin SJ (1991) Alcohol and aldehyde dehydrogenase genotypes and alcoholism in Chinese men. American Journal of Human Genetics 48, 677-681.

Wenger NK (1996) Gender differences in coronary risk and risk factors. In Prevention of Myocardial Infarction, pp. 387-412 [JE Manson, PM Ridker, JM Gaziano and CH Hennekens, editors] New York: Oxford University Press.

Whitehead TP, Robinson D, Allaway S, Syms J \& Hale A (1995) Effect of red wine ingestion on the antioxidant capacity of serum. Clinical Chemistry 41, 32-35.

Whitfield JB (1994) ADH and ALDH genotypes in relation to alcohol metabolic rate and sensitivity. Alcohol and Alcoholism 2, Suppl., 59-65.

Whitfield JB, O'Brien ME, Nightingale BN, Zhu G, Heath AC \& Martin NG (2003) ADH genotype does not modify the effects of alcohol on high-density lipoprotein. Alcoholism, Clinical and Experimental Research 27, 509-514.

Yuan JM, Ross RK, Gao YT, Henderson BE \& Yu MC (1997) Follow-up study of moderate alcohol intake and mortality among middle aged men in Shanghai, China. British Medical Journal 314, 18-23. 